\title{
Uma questão de timing: aspectos da consagração de José Saramago no Brasil
}

\author{
MARGarida Rendeiro \\ Universidade Lusíada (Lisboa, Portugal)
}

RESUMO: O PRESENTE ARTIGO IDENTIFICA OS TRÊS FACTORES FUNDAMENTAIS QUE DETERMINARAM O SUCESSO EDITORIAL DE JOSÉ SARAMAGO NO BRASIL: A ESCOLHA DO MOMENTO CERTO DA PUBLICAÇÃO DE CADA UMA DAS OBRAS, DE ACORDO COM A EVOLUÇÃO DO CONTEXTO POLITICO, SOCIAL E CULTURAL; A CONSTRUÇÃO DA SUA BIOGRAFIA ORIENTADA; E A IMPORTÂNCIA DAS EDITORAS QUE PUBLICARAM A SUA OBRA. O AUTOR BENEFICIOU DAS RELAÇÕES DOS AGENTES DE PRODUÇÃO E REPRODUÇÃO LITERÁRIAS QUE REFORÇARAM A VISIBILIDADE NO CAMPO LITERÁRIO, COMBINANDO O PRESTÍGIO LITERÁRIO E O SUCESSO COMERCIAL.

ABSTRACT: THIS PAPER ESTABLISHES THE THREE KEY FACTORS THAT DETERMINED THE SUCCESS OF JOSÉ SARAMAGO IN BRAZILIAN LITERARY MARKET: THE CHOICE OF THE RIGHT TIMING OF PUBLICATION OF HIS WORKS ACCORDING TO THEIR POLITICAL, SOCIAL AND CULTURAL ENVIRONMENT; THE CONSTRUCTION OF HIS BIOGRAPHY; AND THE RELEVANCE OF HIS PUBLISHING HOUSES. SARAMAGO'S PRESTIGE BENEFITTED FROM THE RELATIONS BETWEEN DIFFERENT AGENTS OF LITERARY PRODUCTION AND REPRODUCTION, ENHANCING THEIR VISIBILITY IN THE FIELD, AND COMBINING LITERARY PRESTIGE AND COMMERCIAL SUCCESS.

PALAVRAS-CHAVE: JOSÉ SARAMAGO, MERCADO, EDITORA, BIOGRAFIA.

KEYWORDS: JOSÉ SARAMAGO, MARKET, PUBLISHING HOUSE, BIOGRAPHY. 
onseguir ser publicado pela editora certa e ter uma recenção assinada pelos críticos adequados no momento apropriado é fundamental quando se trata de obter reconhecimento e prestígio literários. Por momento apropriado, entende-se a publicação de uma obra cuja temática se relacione, de alguma maneira, com o contexto político, cultural e cultural do país em que essa obra seja publicada. É isso que traz visibilidade à qualidade literária. A importância das editoras no respectivo mercado editorial e as suas políticas de comunicação desempenham uma função primordial para a obtenção de um determinado impacto. A gestão do momento adequado à publicação da obra de José Saramago no Brasil foi essencial para reforçar o prestígio do autor.

As teorias de sistemas literários permitem compreender as relações complexas que envolvem os diferentes agentes de produção, reprodução e consagração literária, ou seja, escritores, editores, críticos, livreiros e leitores, no momento em que determinados textos são escolhidos, lidos e premiados em detrimento de outros, consoante os contextos político, social e cultural envolventes.

Na década de 1970, Pierre Bourdieu descreveu o campo literário como um microcosmo social regido pelas suas próprias estruturas e leis. Desenhava-se o espaço das relações objectivas entre diferentes posições e cada posicionamento dependia da relação com os demais. As circunstâncias políticas, sociais e culturais exerciam pressão e a própria estrutura de relações dinâmicas do campo alterava-se, numa luta contínua de preservação e transformação da ordem. Estudar estas transformações permitia compreender as relações entre escritores, críticos e editores, e a importância que uma obra assume num dado período histórico. Bourdieu salientou igualmente que o princípio da legitimidade no campo do poder assenta na obtenção do chamado capital económico ou político. A expressão "capital simbólico" é central na investigação de Bourdieu e refere-se ao prestígio acumulado, consagração e honra, assentes na dialéctica entre o conhecimento e o reconhecimento literários. No presente artigo, esta expressão refere-se ao prestígio acumulado de José Saramago e dos seus editores e, particularmente aos benefícios ou ganhos acrescentados ao lucro financeiro.

Jacques Dubois, cuja investigação prosseguiu a partir do contributo de Bourdieu, desenvolveu a Teoria da Instituição Literária. Em 1978, Dubois adiantou que a criação literária era condicionada pelos constrangimentos 
inerentes ao próprio mercado e que os escritores participavam no sistema com o intuito de obter o reconhecimento ou prestígio literários. Este autor classificou as autoridades que conferem legitimidade à produção literária, incluindo na sua lista os movimentos literários (integradores de novos autores, posicionando-os em relação a uma autoridade legitimidada), editores e livreiros (seleccionadores e promotores da produção literária), academias (comentadores oficiais cujo sistema de prémio literário serve um determinado posicionamento no campo literário) e o sistema educativo (integrador de práticas literárias num conjunto de normas orientadoras da leitura).

Bourdieu diferenciou o campo da produção literária restrita (a chamada literatura de "qualidade", potencialmente consagrada) do campo de produção literária em larga escala (literatura popular ou de massas). No que diz respeito à produção literária restrita, Bourdieu defendeu que o sistema de relações entre as variadas instâncias se dividiam de forma funcional, de acordo com o seu papel de produção, reprodução e promoção de bens simbólicos. Desenvolviam os seus próprios critérios de avaliação de forma a alcançar o reconhecimento das elites. A hierarquia dependia do sucesso (volume de vendas, prémios e reputação). No que diz respeito à produção em larga escala, o reconhecimento dependia inteiramente do público porque, conforme o autor explicou, este campo era dominado pela procura do máximo lucro. O produto era direccionado para diferentes públicos-alvo, envolvendo uma cultura de marca.

Deste modo, Bourdieu dividiu o negócio literário em "comercial" e "cultural". Um negócio comercial correspondia a uma procura pré-existente, envolvendo curtos ciclos de produção de forma a minimizar os riscos financeiros. Usa técnicas de Marketing, tais como sobre-capas apelativas, sessões de autógrafos, campanhas de publicidade e acções de relações públicas. Utiliza autores com produção literária efémera, tais como jornalistas e celebridades. Um negócio cultural associava-se a longos ciclos de produção, não dispondo de um mercado pré-definido. Sendo uma produção orientada para o future, os stocks poderiam ganhar a categoria de materiais ou mesmo a de objectos culturais. Ao contrário, do outro tipo de produção, dependia fundamentalmente da actividade dos editoras como caça-talentos.

Investigadores mais recentes, tais como De Glas e Verdaasdonk, têm demonstrado que a distinção entre negócio cultural e comercial sugerida por Bourdieu não se aplica de uma forma generalizada. Se, por um lado, alguns 
autores com obra escassa contribuem para o prestígio de algumas editoras, por outro lado, muitas editoras funcionam como um estágio para autores em início de carreira literária antes de assinarem com outras editoras de maior importância. Para além disso, acresce o facto de muitas editoras de renome assumirem o risco de publicar autores estreantes e de adoptarem técnicas de promoção, tais como as sessões de autógrafos e campanhas publicitárias que, em Bourdieu, estavam somente associadas a negócios comerciais.

Finalmente, a orientação e promoção de um perfil de autor definido assume relevância na gestão de uma carreira literária. Bourdieu chamou-lhe "trajectória social", ou seja, a construção de uma biografia pública. Dubois acrescentou que o perfil público do escritor era construído por fases ao longo da sua carreira e moldado de acordo com a participação do escritor em movimentos literários, relações estabelecidas com outros agentes literários, prémios, posições publicamente defendidas e a gestão da própria imagem feita pelos editores. Este perfil seria complementado pelo próprio contexto familiar, profissional, político, ideológico e académico do próprio autor.

Partindo dos conceitos inerentes às teorias de sistemas literários formuladas por Pierre Bourdieu e Jacques Dubois, o presente artigo debruça-se sobre os factores que propiciaram a projecção e sucesso literário da obra de José Saramago, partindo da premissa que a conjugação da publicação da obra adequada à conjuntura nacional adequada e a gestão do perfil público do autor determinaram a consagração de Saramago no Brasil. Desta forma, analisam-se as editoras que o publicaram, a recepção da obra na imprensa e no mercado brasileiro bem como depoimentos e posições assumidas pelo autor num período compreendido entre a publicação do primeiro romance, em 1982, e a atribuição do Prémio Nobel em 1998.

\section{II}

A DIFEL foi a editora que publicou Levantado do chão no Brasil em 1982. DIFEL - Difusão Editorial, S.A. foi o nome escolhido pela editora Bertrand Brasil em 1974 e o catálogo desta editora incluía variados autores, tais como Pablo Neruda, Autran Dourado, Jorge Luís Borges e Isabel Allende. A Bertrand Brasil tinha sido fundada em 1949 com o objectivo principal de im- 
portar livros portugueses e franceses. Em 1986, a DIFEL foi comprada pela editora portuguesa Bertrand Editora e adoptou o nome Editora Bertrand Brasil. ${ }^{1}$ A Bertrand Brasil comprou a Editora Civilização Brasileira e alargou o seu catálogo com autores brasileiros e estrangeiros que incluíam José J. Veiga, Dias Gomes, Alberto Moravia, Noam Chomsky e Ernest Hemingway, entre outros. Em 1988, a DIFEL deixou de publicar as obras de José Saramago quando a Editora Caminho, editora portuguesa do autor, negociou um contrato com a Companhia das Letras que se tornou a sua editora no Brasil.

Ao contrário do que aconteceu com as editoras americanas e inglesas - e à semelhança do que aconteceu com as editoras espanholas - as editoras brasileiras publicaram não só os romances de Saramago, mas também os seus ensaios, poesia e peças de teatro. A Companhia das Letras publicou o livro de viagens Viagem a Portugal, as peças de teatro In nomine Dei e Que farei com este livro?, os diários Cadernos de Lanzarote, os contos Objecto quase e as crónicas $A$ bagagem do viajante.

A escolha das obras variou de país para país. Considerando apenas o caso brasileiro e espanhol, Que farei com este livro? foi apenas publicado no Brasil, enquanto que $A$ noite e $O$ ano de 1993 foram publicados em Espanha. As decisões do editor são reveladoras do facto de que o conteúdo de qualquer das obras não é considerado potencialmente interessantes de forma generalizada.

A narrativa Levantado do chão é enquadrada pelas mudanças sociais que modificaram Portugal entre o final da monarquia e o despoletar da Revolução de 1974. O infortúnio e miséria de três gerações de uma mesma família de camponeses sem terra no Alentejo, que tentam desesperadamente ganhar o sustento em tempos de repressão, foi publicado no período em que surgiu um movimento de camponeses sem terra no Brasil, com o apoio de diversas personalidades ligadas ao mundo das artes. ${ }^{2}$

O Brasil tinha atravessado os derradeiros anos de um governo militar. As primeiras eleições democráticas realizaram-se em 1985, quando Tancredo Ne-

1. Levantado do chão foi publicado em 1982 com as chancelas da DIFEL e da Bertrand Brasil e Memorial do convento foi publicado pela DIFEL em 1983 e pela Bertrand Brasil em 1987.

2. Por exemplo, em 1982, quando Levantado do chão foi publicado no Brasil, Milton Nascimento cantava Missa dos Quilombos, defendendo a igualdade de oportunidades para os trabalhadores negros sem terra no Brasil. D. José Maria Pires, arcebispo de João Pessoa e D. Helder Câmara, arcebispo de Olinda e Recife, apoiaram esta causa. 
ves, do MDB, foi eleito Presidente. Contudo, não chegou a tomar posse, tendo subitamente falecido durante uma cirurgia de emergência, e substituído pelo seu Vice-Presidente José Sarney, que governou o país até 1990. O MDB - Movimento Democrático Brasileiro - foi apoiado por personalidades que tinham participado na oposição aos governos militares. Num período em que emergiam os movimentos em defesa dos direitos dos trabalhadores, o tema abordado em Levantado do chão tornava-se potencialmente interessante para os leitores brasileiros. É de salientar que, não obstante o autor ser natural de um país historicamente próximo do Brasil, a literatura portuguesa contemporânea era relativamente desconhecida naquele país. ${ }^{3}$ A História une ambos os países, e o romance de Saramago salientava como alguns aspectos da História do passado recente de Portugal se espelhavam no momento histórico brasileiro presente.

A escolha deste romance orientou a apresentação de Saramago no Brasil: um autor cujas ideias políticas eram abertamente discutidas em entrevistas e que apoiava os direitos dos sem-terra. Quinze anos depois da publicação de Levantado no chão, Saramago prefaciou Terra, um livro de fotografias sobre aqueles trabalhadores sem-terra de autoria de Sebastião Salgado, publicado pela Companhia das Letras, e que chama à atenção do público para as reformas agrárias no Brasil. ${ }^{4}$

A promoção de José Saramago no Brasil foi assente na construção da sua trajectória social, nomeadamente na escolha de aspectos da sua vida, experiência e posições ideológicas, que o legitimavam enquanto autor socialmente comprometido. Numa entrevista ao Folha de S. Paulo, Saramago ressalvou a co-existência pacífica entre a escrita e a sua filiação no Partido Comunista:

\footnotetext{
3. No Brasil, onde o conhecimento da literatura vinda do chamado "país irmão" muitas vezes não passa de Fernando Pessoa, Saramago é o mais popular autor português e tem os seus livros nas listas dos mais vendidos por várias semanas (Köninger, 2004).

4. Esta preocupação pode ser enquadrada na promoção do autor fundamentada nas origens operárias e nas ideias comunistas. Esta imagem foi promovida de forma consistente entre 1982 e 2004. Saramago foi ao Brasil para uma série de entrevistas e outras apresentações públicas, juntamente com Sebastião Salgado e Chico Buarque de Hollanda que compôs um CD para ser lançado em conjunto com o livro. O lançamento foi coberto pela imprensa brasileira em Abril de 1997. Marili Ribeiro escreveu no Jornal do Brasil: 'O presidente Fernando Henrique Cardoso poderia entrar para a história do Brasil como o homem que fez a reforma agrária no país. Dessa concepção comungam três monstros sagrados do universo artístico: o fotógrafo Sebastião Salgado, o escritor português José Saramago e o compositor e cantor Chico Buarque de Hollanda' (13 Abril 1997, p. 14).
} 
Sou dentro e fora desse partido - fora quando não estou em relação direta com ele, dentro quando há o momento, quando estou em seu nome -, digamos assim, há uma perfeita lealdade, de perfeita responsabilidade e de perfeita liberdade. Quer dizer, eu escrevo exatamente o que quero, exatamente como quero, sem nenhuma prévia determinação, orientação, conselho, aviso, prevenção, arranjo todas as palavras que quiserem, vindas directa ou indiretamente do meu partido. E por uma razão imediata e simplicíssima, é que eu sendo convictamente aquilo que sou, também convictamente acho que o meu partido não é competente em matéria literária. (SARAMAGO, 1989) ${ }^{5}$

De acordo com dados estatísticos, e malgrado o mercado editorial brasileiro ser o oitavo no ranking de produção literária mundial, o analfabetismo atingia cerca de 38\% da população em 2004 e apenas 16\% comprava $73 \%$ dos livros publicados. ${ }^{6}$ Embora não haja inquéritos que suportem a evidência sobre a compra de ficção portuguesa no Brasil (e que incluam segmentação de consumidores), a construção do perfil de Saramago como homem da classe operária, socialmente comprometido e conhecedor dos problemas que afligiam a realidade brasileira seria uma forma de despertar o interesse de potenciais leitores brasileiros, reforçando o seu capital simbólico.

As opiniões de Saramago sobre religião foram igualmente um dos tópicos abordados em entrevistas. Foram publicadas dois anos antes do lançamento d' O evangelho segundo Jesus Cristo e, em retrospectiva, podem ser lidas como formas de moldar a perceção dos leitores brasileiros relativamente às suas obras que abordam a religião. Até 1989, apenas quatro romances tinham sido publicados e nenhum deles se relacionava com a religião. $O$ evangelho segundo Jesus Cristo e In nomine Dei foram publicados no início da década de 1990.

Quando In nomine Dei foi lançado no Brasil, as três edições em Portugal em apenas três meses tornou-se evidência do valor literário de Saramago:

5. 'Saramago conversa sobre o Ofício de Escritor', Folha de S. Paulo, 6 Maio 1989. Disponível em: http://www1.folha.uol.com.br/folha/almanaque/entsaramago.htm. Acedido em Maio 2010. Nessa entrevista, Saramago fala de si próprio como um homem simples, ligado à sua velha máquina de escrever (na qual tinha escrito o livro publicado no Brasil nesse ano) e que apenas usava computadores por causa do imperativo da modernização.

6. Estatísticas disponíveis em http://www.cbl.org.br/news.php?recid=1119\&hl=oitavo, visitado em Março 2005.

7. Ver, a título de exemplo, 'Saramago conversa sobre o ofício de Escritor'. 
De um ateu, podem-se esperar anátemas e blasfêmias contra os códigos religiosos. Mas de um ateu como o escritor português José Saramago, podem-se esperar investidas em temas religiosos como mais uma forma de redimensionar seu universo ficcional. (LUÍS, 1993, p. 3)

Uma leitura atenta aos artigos que se referem a Saramago até 1998 evidencia que a consagração literária do autor ficou claramente definida no início da década de 1990. O reconhecimento (de críticos e leitores) do mérito do autor com a atribuição do Prémio Camões e do Prémio Nobel foi tornado público em $1993 .{ }^{8}$

Em 1994, a publicação de Objecto quase recebeu críticas favoráveis e a reputação de Saramago no Brasil ficou clara na crítica assinada por Paulo Amador:

Saramago dispensa apresentação, de tal modo tem sido abundante e merecidamente receptiva a crítica brasileira a esse desconcertante escritor português pós-moderno. Pós-moderno? Seja. Em livros anteriores. [...] Por tudo isso, é mesmo bom que se leia Saramago, neste seu Objecto quase. Até para se descobrir que, na linha da totemização da palavra, há no Brasil uma excelente produção de livros de contos. (AMADOR, 1994, p. 3) ${ }^{9}$

Ao contrário de outros países, como por exemplo, os Estados Unidos, no Brasil, não houve qualquer alusão directa ao Realismo Mágico. Os críticos brasileiros associaram Saramago às tendências pós-modernistas. ${ }^{10}$ Os jornais

8. Jornal do Brasil publicou na secção 'Opinião dos Leitores', uma carta de um leitor afirmando que Saramago merecia receber o Prémio Camões e o Prémio Nobel em 1994. (15 Julho 1993, [n.p]). Jorge Amado, autor consagrado, sugeriu Saramago para o Prémio Nobel em 1994, embora o autor português não fosse a sua primeira escolha; na opinião de Amado, Miguel Torga seria o autor português cuja obra merecia a atribuição do prémio Nobel. Cf. Otávio Dias, 'Llosa é um escritor clássico', Folha de S. Paulo, 27 Novembro 1994, p. 6-7.

9. Igualmente relevante é a crítica de Bob Fernandes publicada em Folha de S. Paulo (12 Janeiro 1994, p. 5-1), na qual compara alguns dos contos em Objecto quase à vida quotidiana de São Paulo.

10. Ao contrário do publicado na imprensa de língua inglesa, a imprensa brasileira pediu a diversas personalidades brasileiras para recomendar um livro aos leitores brasileiros. Muitas delas recomendaram obras de Saramago: por exemplo, Chico Alencar (escritor), Carlos Zara (actor), e Ricardo Tacuchian (professor) recommendaram a leitura de $O$ evangelho segundo Jesus Cristo; e Pepita Rodrigues (actriz e escritora) sugeriu $A$ jangada de pedra. Cf. 16 'O que eles estão lendo', Jornal do Brasil, 25 Setembro 1993, p. 6; 'O que eles estão lendo', Jornal do Brasil, 13 Maio 1995, p. 6; 'O que eles estão lendo', Jornal do Brasil, 3 Junho 1995, p. 6; 'O que eles estão lendo em Frankfurt', Jornal do Brasil, 24 Setembro 1995, p. 6. 
brasileiros davam conta do sucesso do autor português nos Estados Unidos, incluindo a recepção positiva de $O$ evangelho segundo Jesus Cristo (VILLA-BOAS, 1994, p. 2). Numa entrevista à Folha de S. Paulo, aquando o lançamento d' $O$ cânone ocidental (The western canon), Harold Bloom apontou Saramago como um dos autores de expressão portuguesa no seu cânone. (PISA, 1994, p. 5-6)

Os jornais brasileiros publicaram alguns dos textos originalmente publicados no El País. A Folha de S. Paulo publicou dois em 1994, ambos sobre Lisboa, reflectindo os interesses do autor sobre o seu país e cidade:

Dir-se-ia que pouco interessam essas miudezas históricas. Estou de acordo, mas interessaria muito - a mim, pelo menos - não apenas saber, mas também ver, no sentido mais exato da palavra, como Lisboa vem mudando daqueles tempos remotos até hoje. (SARAMAGO, 22 Setembro 1994, p. 6-17)

Minha Lisboa foi sempre a dos bairros pobres, e quando, muito mais tarde, as circunstâncias e as mudanças da vida me levaram a viver em outros rios e ambientes, a memória que mais ciumentamente quis conservar, até hoje, foi a da Lisboa dos meus primeiros anos, [...]. Basta que Lisboa seja o que simplesmente deve ser: feliz, culta, moderna, limpa, organizada, sem perder nada da sua alma antiga. (SARAMAGO, 18 Setembro 1994, p. 6-17)

Ambos os artigos foram publicados sob o título: "O País de Saramago" na secção de "Turismo". Este facto soa contraditório, uma vez que os textos supramencionados não recomendam uma qualquer visita turística a Lisboa, no sentido em que um guia turístico o faria. Aquelas eram viagens através de uma cidade que não existia mais e que apenas poderiam existir na mente de Saramago. Conforme afirmara, as suas memórias eram o resultado da experiência pessoal enquanto pessoa de origens humildes. São textos que se assemelham a Viagem a Portugal, publicado em Portugal em 1980. Nos textos publicados no Folha de S. Paulo, Saramago não rejeitou inteiramente a Lisboa moderna; no entanto, apelou à necessidade de preservar a tradição e ao respeito pelos trabalhadores e camponeses que fizeram a capital. Estes artigos conferem um cunho mais pessoal ao autor que defendeu os direitos dos trabalhadores no Brasil.

As entrevistas de Saramago focaram igualmente o Iberismo como forma de juntar Portugal e o Brasil: 
Há uma coisa que é o bem comum, a língua, que é a coisa mais importante que nós deixamos no Brasil. A língua, que foi o elemento de unidade neste país imenso. A questão é saber se os portugueses e os brasileiros têm consciência deste bem comum num mundo como este em que vivemos. (FERNANDES, 1994 , p. $5-6)^{11}$

As opiniões do autor apareceram como importantes contributos no âmbito da discussão sobre a "nação pan-ibérica", defendida por Saramago, reforçando - em termos de projecção de imagem de autor - o seu interesse pelos problemas brasileiros.

No que diz respeito à participação de Saramago no saneamento ocorrido no jornal diário português Diário de Notícias em 1975, a Folha de S. Paulo referiu-se a ela em termos diversos ao descrito em Portugal: foi acrescentado que Saramago tinha sido dos poucos que tinham escapado ao controlo da censura e conseguira publicar informação sobre a Guerra Colonial (NERY, 2004). Uma imagem mais positiva desse incidente pode ser relacionada com a inexistência de um certo envolvimento emocional e experiência da Revolução que definiu aqueles que acusaram Saramago em Portugal. No Brasil, a experiência do governo militar e instabilidade política era recente e, consequentemente, o incidente suscitava potencial interesse (familiaridade). Pelo contrário, este incidente foi ignorado em outros países onde Saramago foi traduzido, nomeadamente no mundo anglo-americano.

Luiz Schwarcz, editor de Companhia das Letras, foi entrevistado em 2004, tendo afirmado que um editor devia desempenhar o papel de "interventor cultural, intervém com as suas escolhas". Esta editora tem publicado ensaios, poesia e ficção. A importância da História foi explicitada na forma como a editora se apresentava e apresentava a obra de Saramago. Os textos publicitários que apresentavam os romances do autor português usavam expressões, tais como "recriar o passado e o presente" e "a aventura ficcional da desconcertação das certezas das palavras [...] reencontram-se em signos velhos”. Estas expressões sublinham a importância do Novo Historicismo em Sara-

11. Outro exemplo é a entrevista concedida a Köninger. 'Uma das questões que o Brasil teria de resolver na sua relação conosco é saber quando começa a literatura de língua portuguesa para vocês. [...] Portanto, essa espécie de pan-Iberianismo, sem qualquer intenção imperial, evidentemente seria qualquer coisa a criar ou renovar.' 
mago. Na entrevista mencionada, Schwarcz apontou igualmente a importância das obras sobre História para a sua editora:

Por exemplo: que tal publicar uma historiografia que está produzindo obras bastante inovadoras, que traz a história para a vida cotidiana, traz para o Brasil uma nova história chamada história das sensibilidades, história das mentalidades, que ao mesmo tempo é nova no Brasil e tem interesse e importância para o público de historiadores, e atinge um público mais amplo.

A importância da editora na construção de um autor foi reforçada na investigação de Frank de Glas, Wouter de N. Nooy and Verdaasdonk. ${ }^{12}$ No que concerne às obras de Saramago, e tendo em consideração o perfil da editora, a obra do autor português enquadrava-se na política da Companhia das Letras. Os comentários públicos do autor sobre a sociedade em geral e sobre os direitos dos trabalhadores reforçavam a sua autoridade a ponto de se tornar um dos escritores portugueses mais populares. O facto de utilizar uma língua comum facilitou a exposição pública de Saramago. Era frequentemente solicitado a comentar sobre aspectos da política brasileira, tendo participado em conferências e seminários. As opiniões publicadas do autor focavam a necessidade premente da participação do povo na vida política brasileira. ${ }^{13}$ Para além disso, Saramago prefaciou livros de autores brasileiros, tais como Sebastião Salgado e Horácio Costa. ${ }^{14}$ A disputa com Autran Dourado sobre o Acordo Ortográfico negociados entre os Governos dos Países de Expressão Portuguesa garantiu-lhe uma relativa exposição na imprensa brasileira. ${ }^{15}$ No

12. No decurso da disputa entre Saramago e Autran Dourado, o escritor brasileiro declarou: 'José Saramago é grande escritor, mas ele só é lido aqui por ter sido editado por uma editora brasileira'. Citado em "Frases", Folha de S. Paulo, 23 Fevereiro 1994, p. 5-6.

13. Fernandes: 'Para falar com franqueza, ou o povo brasileiro intervém na sua própria vida - o povo, não os segmentos políticos que o representam - torna isto uma prática cotidiana, ou tudo continuará como sempre foi antes'.

14.Joyce Pascowitch, 'Entrelinhas', Folha de S. Paulo, 11 Dezembro 1994, p. 6-2. 'Com direito a prefácio mais que ilustre - de José Saramago, Horácio Costa autografa quarta-feira na Livraria Cultura seu Menino e o travesseiro'.

15. A título de comparação, em Portugal, o alarido sobre Dinossauro Excelentíssimo de José Cardoso Pires em 1972 levou a uma procura massiva do livro nas livrarias. Em Espanha, a imprensa referiu-se à troca de crítica entre Vargas Llosa e Saramago em 1990, ambos publicados pela Alfaguara, tendo estes autores figurado na lista dos livros mais comprados. 
Brasil, os livros de Saramago figuraram nas listas dos livros mais vendidos. É difícil aferir a relevância destas disputas para o incremento das vendas de autores conhecidos, mas o facto é que elas reforçam a publicidade em torno dos autores, e, consequentemente, reforçam o capital simbólico das editoras.

O envolvimento de Saramago em disputas reforçou a sua autoridade e consagração, em particular num momento em que foi incluído na lista de obras de leitura obrigatória para os exames do vestibular em 1995. Saramago foi o único autor português vivo a ser incluído nesta lista, com a obra Memorial do convento. Os outros autores portugueses foram Eça de Queirós, Bocage e Fernando Pessoa (Folha de S. Paulo, 8 Novembro 1994, p. 7). Só dois autores vivos foram acrescentados à lista de leituras obrigatórias: Saramago e Rubem Fonseca, ambos publicados pela Companhia das Letras que igualmente beneficiou com uma subida das vendas dos livros destes autores. ${ }^{16}$

O Prémio Nobel de 1998 foi anunciado por jornalistas e por Saramago como sendo um pouco do Brasil. A ênfase foi colocada no facto de ser atribuído a um autor de língua portuguesa, o que merecia uma celebração no Brasil. ${ }^{17}$

\section{III}

Considerar a consagração de José Saramago sem atender ao seu contexto político-social e ao debate cultural é obliterar um entendimento do próprio processo de consagração literária do autor. As teorias sistémicas auxiliam na interpretação destes fenómenos. Os aspectos salientados neste artigo permitem concluir que José Saramago, enquanto autor português publicado fora do seu país de origem, participou de forma activa na construção da sua própria trajectória social, orientando aspectos da sua vida pessoal e revelando

16.Arthur Nestrovski, “Os dez mais melancólicos”, Folha de S. Paulo, 16 Outubro 1994, p. 6-7. O facto de Memorial do convento, de José Saramago e $A$ grande arte, de Rubem Fonseca subirem a nona e décima posições é explicada pela inclusão destas obras nos exames da FUVEST.

17.Cf. "Prémio para a Língua Portuguesa", Estado de Minas, 9 Outubro 1998. Saramago declarou "A literatura brasileira não precisa que um escritor português abra caminho para chegar a um Nobel. Até mesmo se deve dizer que os brasileiros já deveriam ter ganhado antes o Nobel e então eles é que abririam o caminho para a literatura portuguesa. Eles é que mereciam ganhar mais do que eu. A verdade é que os escritores brasileiros, Cabral, Amado, Drummond, teriam sido grandes escolhas", em Graça Magalhães-Ruethe, "Amado e Cabral mereciam o prémio mais do que eu", O Globo, 9 Outubro, 1998. 
posições ideológicas que melhor se adequavam aos momentos de publicação dos seus livros - muito particularmente no momento da publicação do seu primeiro romance. É interessante verificar que, no plano internacional, o primeiro romance de Saramago a ser traduzido nem sempre foi o mesmo em cada país. Em Espanha, o primeiro romance a ser traduzido foi $O$ ano da morte de Ricardo Reis, enquanto que nos Estados Unidos e no Reino Unido, foi Memorial do convento. Este facto mostra, por um lado, que o potencial interesse de um livro varia conforme os vários contextos nacionais e, por outro lado, salienta a necessidade de as trajectórias sociais do autor terem de ser diferentemente construídas consoante o potencial impacto que determinados aspectos biográficos poderão ter nesses mesmos países.

O presente artigo estabelece igualmente a validade da taxonomia proposta por Jacques Dubois relativamente às autoridades legitimadoras do capital simbólico de Saramago. A análise mostrou o papel activo do escritor, editora, imprensa, academias e do Governo, enquanto órgão decisor em matéria de Educação no processo de legitimação de Saramago no Brasil.

Finalmente, o facto de terem sido explorados artigos de imprensa neste artigo sublinha a importância dos meios de comunicação social no processo de consagração de um autor que claramente se afasta da tradicional classificação "literatura popular". E neste aspecto, mais uma vez se confirma que a diferenciação dos processos de legitimação consoante a actividade seja eminentemente cultural ou comercial, conforme proposta por Pierre Bourdieu, não se aplica ao objecto de análise. Pelo contrário, acentua a importância dos mecanismos de promoção no processo gradual de identificação do autor com um mercado editorial novo.

\section{Referências bibliográficas}

AMADOR, Paulo. Saramago se rende ao culto à palavra. Escritor opta pela experimentação sem abandonar a beleza do texto. Jornal do Brasil, Rio de Janeiro, 2 Abril 1994, p. 3.

BOURDIEU, Pierre. The Field of Cultural Production. Essays on Art and Literature. Edited and introduced by Randal Johnson. Cambridge: Polity Press \& Blackwell Publishers Ltd, 1993. 
BOURDIEU, Pierre. Distinction - a social critique of the judgement of taste. Londres: Routledge \& Kegan Paul Ltd, 1986.

CÂMARA BRASILEIRA DO LIVRO. Disponível em: < http://www.cbl.org.br/news. php?recid=1119\&hl=oitavo $>$. Acedido em Março 2005.

CHICARETI, Marco. Acordo ortográfico cria nova polémica. Folha de S. Paulo, São Paulo, 23 Fevereiro 1993, p. 5-3.

DE GLAS, Frank. Authors' oeuvres as the backbone of publishers' lists: studying the literary publishing house after Bourdieu. Poetics, n. 25, 1998, p. 379-397.

DE GLAS, Frank. Literature, In-House Writers, and Processes of Success in Publishing. Trad. Ann Rigney. CLC Web: Comparative Literature and Culture. Disponível em: <http:// www.art.ualberta.ca/clcwebjournal/clcweb99-4/deglas99>. Visitado em Janeiro 2000.

DE NOOY, Wouter. Gentlemen of the Jury... The features of experts Awarding Literary Prizes. Poetics, n. 17, 1988, p. 531-545.

DIAS, Otávio. Llosa é um escritor clássico. Folha de S. Paulo, São Paulo, 27 Novembro 1994, p. 6-7.

DUBOIS, Jacques. L'institution de la littérature. Brussels: Editions Labor/Ferdinand Nathan, 1986.

FERNANDES, Bob. Monstro da Intolerância voltou, diz Saramago. Folha de S. Paulo, São Paulo, 12 Janeiro 1994, p. 5-1.

FRASES. Folha de S. Paulo, São Paulo, 23 Fevereiro 1994, p. 5-3.

LUÍS, Macksen. Sangrento episódio da Reforma inspira nova peça de Saramago. Jornal do Brasil, Rio de Janeiro, 7 Agosto 1993, p. 3.

MAGALHÃES-RUETHER, Graça. Amado e Cabral mereciam o prémio mais do que eu. Estado de Minas, Belo Horizonte, 9 Outubro 1998.

NESTROVSKI, Arthur. Os dez mais melancólicos. Folha de S. Paulo, São Paulo, 16 Outubro 1994, p. 6-7.

O QUE eles estão lendo. Jornal do Brasil, Rio de Janeiro, 13 Maio 1995, p. 6.

O QUE eles estão lendo. Jornal do Brasil, Rio de Janeiro, 25 Setembro 1993, p. 6.

O QUE eles estão lendo. Jornal do Brasil, Rio de Janeiro, 3 Junho 1995, p. 6.

O QUE eles estão lendo em Frankfurt. Jornal do Brasil, Rio de Janeiro, 24 Setembro 1995, p. 6.

O QUE muda nos vestibulares. Folha de S. Paulo, São Paulo, 8 Novembro 1994, p. 7. PASCOWITCH, Joyce. Entrelinhas. Folha de S. Paulo, São Paulo, 11 Dezembro 1994, p. 6-2.

PISA, Daniel. Erramos. Folha de S. Paulo, São Paulo, 25 Agosto 1994, p. 5-1.

PRÊMIO para a Língua Portuguesa. Estado de Minas, Belo Horizonte, 9 Outubro 1998.

RIBEIRO, Marília. Autores de "Terra” acreditam que FH pode fazer reforma. Jornal do Brasil, Rio de Janeiro, 13 Abril 1997, p. 14. 
SARAMAGO conversa sobre o Ofício de Escritor. Folha de S. Paulo, São Paulo, 6 Maio 1989. Disponível em: <http://www.folha.uol.com.br/folha/almanaque/entsaramago.htm>. Visitado em 22 Setembro 2004.

SARAMAGO, José. Capital abandona marasmo e indiferença. Folha de S. Paulo, São Paulo, 18 Setembro 1994, p. 6-17.

SARAMAGO, José. Transformação de Lisboa daria um filme. Folha de S. Paulo, São Paulo, 22 Setembro 1994, p. 6-17.

VILLAS-BOAS, Luciana. Informe/Idéias. Jornal do Brasil, Rio de Janeiro, 21 Maio 1994, p. 2.

KÖNINGER, Bete. Atenção, este livro leva uma pessoa dentro. Disponível em: <http:// www.is-koeln.de/matices/16/16ksaram.htm>. Visitado em 29 Abril 2004.

Recebido em 04 de maio e aprovado em 21 de junho de 2011. 